\title{
Island Operations of Electric Generators Connected to One Substation
}

\author{
Petr Neuman \\ NEUREG Association, Prague, Czech Republic, e-mail: neumanp@volny.cz
}

\begin{abstract}
While increasing integration of renewable energy sources (RES), which are unregulated and difficult to predict, a large system of nuclear power plants must provide balancing peaks in the production of renewable energy. It is also important to simulate the rapid changes in the power of individual large Nuclear Power Plant (NPP) units, and for these regimes to train operators of nuclear units. Therefore the paper is aimed to island operations of more parallel electric synchronous generators connected to one substation of a power grid.
\end{abstract}

Keywords - smart grids, transmission and distribution systems, inter-area oscillation mode, island operations of large power plants, power and heating power plant, nuclear power plant, engineering and training simulators

\section{INTRODUCTION}

In the process the building of new smart grids the transmission and distribution systems remain more or less unchanged. At present for classic types of electrical networks it is very negative impact of increasing wind power generation on the North-South Inter-Area Oscillation in the European ENTSO-E System [15]. Therefore in transmission and distribution systems the implementation and benefits of the SMART GRID methods must arise in the coming years, especially from larger, more sophisticated intelligent deployment and application of advanced methods and equipment, such as engineering and training simulators. The dynamic models for simulators in the close critical states are the most important [5].

For the control of rapid and poorly predicted power peaks / deviations it is also necessary to use nuclear power plants. These control requirements are not yet required to NPP and therefore NPP Simulators cannot be used for these purposes. Firstly, there are described the results of the case study: Engineering and training simulators for large conventional and nuclear power plants. Initially there are presented the simulations of different island operations of the power plant turbine generators connected to one substation into the power grid on the example of the power and heating plant with six parallel operating synchronous generators. Generally the power/performance $\mathrm{K}$-Factor (KF) is defined for the T\&D Systems. The KFactor characterizes the electrical properties of the systems. On the simulator the instructor chooses the size distribution system (i.e., KF) in which generators are electrically connected. For different island operations (whose electrical "hardness" depends on the size of KF) it will be shown the results of the simulations on the Dispatcher Training Simulator (DTS) used for the training of parallel operations of two or more power turbine generators / blocks. The simulation models are created in MATLAB - SIMULINK. Secondly, a similar multi-block island mode will be also analyzed for a large Nuclear Power Plants.

TABLE I.

BASIC PARAMETERS OF SELECTED CZECH SYNCHRONOUS GENERATORS

\begin{tabular}{|c|c|c|c|}
\hline $\begin{array}{l}\text { PARAMETERS } \\
\text { OF POWER } \\
\text { PLANTS }\end{array}$ & $\begin{array}{l}\text { OPATOVICE } \\
\text { (EOP) }\end{array}$ & $\begin{array}{l}\text { MĚLNÍK } \\
\text { (EME III) }\end{array}$ & $\begin{array}{l}\text { TEMELÍN } \\
\text { (JETE 1000) }\end{array}$ \\
\hline Pn [MW] & 60 & 500 & 1000 \\
\hline Sn [MVA] & 62.5 & 588 & 1111 \\
\hline $\cos \varphi$ & 0.8 & 0.85 & 0.9 \\
\hline Un [kV] & 10.5 & 20 & 24 \\
\hline $\operatorname{In}[\mathrm{A}]$ & 3437 & 17000 & 26726 \\
\hline$\eta[\%]$ & 98.8 & 98.75 & 98.1 \\
\hline $\begin{array}{l}\mathrm{X}_{\mathrm{DS}} \\
\mathrm{X}_{\mathrm{DN}}\end{array}$ & 2.23 & $\begin{array}{l}2.44 \\
2.66\end{array}$ & 2.8 \\
\hline $\begin{array}{l}\mathrm{X}_{\mathrm{QS}} \\
\mathrm{X}_{\mathrm{QN}}\end{array}$ & 2.10 & $-\overline{2.41}$ & 2.57 \\
\hline $\begin{array}{l}\mathrm{X}_{\mathrm{DS}}^{\prime} \\
\mathrm{X}_{\mathrm{DN}}\end{array}$ & 0.25 & $\begin{array}{l}0.276 \\
0.325\end{array}$ & 0.38 \\
\hline $\begin{array}{l}\mathrm{X}_{\mathrm{QS}} \\
\mathrm{X}_{\mathrm{QN}}\end{array}$ & 0.42 & - & \\
\hline $\begin{array}{l}\mathrm{X}_{\mathrm{DS}} " \\
\mathrm{X}_{\mathrm{DN}}{ }^{\prime \prime}\end{array}$ & 0.15 & $\begin{array}{l}0.226 \\
0.266\end{array}$ & 0.26 \\
\hline $\begin{array}{l}\mathrm{X}_{\mathrm{QS}} " \\
\mathrm{X}_{\mathrm{QS}}\end{array}$ & 0.16 & $(0.286)$ & \\
\hline $\begin{array}{l}\mathrm{T}_{\mathrm{D}}{ }^{\prime}[\mathrm{s}] \\
\mathrm{T}_{\mathrm{DN}}[\mathrm{s}]\end{array}$ & 0.85 & $\begin{array}{l}1.10 \\
0.85\end{array}$ & 1.2 \\
\hline $\begin{array}{l}\mathrm{T}_{\mathrm{QS}}^{\prime}[\mathrm{s}] \\
\mathrm{T}_{\mathrm{QN}}^{\prime}[\mathrm{s}]\end{array}$ & 0.42 & $\begin{array}{l}- \\
-\end{array}$ & \\
\hline $\begin{array}{l}\mathrm{T}_{\mathrm{D}}{ }^{\prime \prime}[\mathrm{s}] \\
\mathrm{T}_{\mathrm{DN}}[\mathrm{s}]\end{array}$ & 0.02 & $\begin{array}{l}0.038 \\
0.022\end{array}$ & 0.033 \\
\hline $\begin{array}{l}\mathrm{T}_{\mathrm{QS}}{ }^{\prime \prime}[\mathrm{s}] \\
\mathrm{T}_{\mathrm{Q}}{ }^{\prime \prime}[\mathrm{s}]\end{array}$ & 0.013 & $\begin{array}{l}- \\
-\end{array}$ & 0.0477 \\
\hline
\end{tabular}




\section{ISLANDING AND RESYNCHRONISING}

The process of synchronization requires the following assumptions and steps in implementation [5]. In practice, when we establish permitted phase error we usually go from the requirement that the initial torque to turn the generator on the network was less than the rated torque.

This usually corresponds to the phase error 8 to $12^{\circ}$. The SYNCHROCHECK realistic device model must be multiphase (three phase) because the device has a real function derived from the measurements of two of the three phases. These measurements are first digitally processed (filtering, reconstruction of the first harmonic components of $50 \mathrm{~Hz}$ ), then the differential voltage between the phases, on the side of both switching objects is set [9].

The described models of SG were used in the training simulators (DTS) of the Czech power plant Opatovice, which consists of six turbogenerators and more substations with different voltage levels $(0.4 \mathrm{kV}, 6.3 \mathrm{kV}$, $10.5 \mathrm{kV}, 110 \mathrm{kV})$. This DTS covers also the electric tielines, which connect plant substation with the $110 \mathrm{kV}$ distribution system of Eastern Bohemia.

The Park's transformation makes a simpler mathematical model of synchronous machines. The advantage is that the electrical parameters (especially mutual inductances) are not functions of time after the transformation [1]. The voltage equations must be completed by two equations of motion.

\section{STATIC AND DYNAMIC STABILITY}

To determine the operating reserve of the static stability and for the dynamic stability parameter (Critical Clearing Time - CCT) calculation by the method of equal areas, it is normally used one-membered performance equation for the active power calculation.

$$
P=\left(U \cdot U_{\text {if }} / x_{\mathrm{d}}\right) \cdot \sin \beta
$$

More accurate calculations, however, we get using the two-member equations, which are also different for static and dynamic stabilities.

Static stability:

$P=\left(U \cdot U_{\text {if }} / x_{\mathrm{d}}\right) \cdot \sin \beta+\left(U^{2} / 2\right) \cdot\left(1 / x_{\mathrm{q}}-1 / x_{\mathrm{d}}\right) \cdot \sin 2 \beta$

where $x_{q} \neq x_{\mathrm{d}}$.

Dynamic stability:

$P=\left(1 /\left(x_{\mathrm{d}+} x_{\mathrm{d}}{ }^{\prime}\right)\right) \cdot U \cdot \psi_{\mathrm{b} 0} \cdot \sin \beta_{\mathrm{s}}-\left(U^{2} / 2\right) \cdot\left(1 /\left(x_{\mathrm{d}}{ }^{\prime}+x\right)\right)-$

$\left.-1 /\left(x_{\mathrm{q}}+x\right)\right) \cdot \sin 2 \beta_{\mathrm{S}}$

where

U stabilized voltage value

$U_{\text {if }} \quad$ fictitious internal voltage induced

$x_{\mathrm{d}} \quad$ direct-axis synchronous reactance

$x_{\mathrm{d}}{ }^{\prime} \quad$ transient reactance

$x_{\mathrm{q}} \quad$ quadrature-axis synchronous reactance

$\beta \quad$ torque angle

$\beta_{\mathrm{S}} \quad$ coupled synchronous angle

Equation (3) is analogous to Eq. (2), but differs in the different member sign with a double load angle. This member will not cancel the machine equations, where $x_{\mathrm{d}^{\prime}} \neq x_{\mathrm{q}}$.
From Table I., and other sources it yields that in all cases:

$$
x_{\mathrm{d}} \neq x_{\mathrm{q}}, \quad x_{\mathrm{d}}^{\prime} \neq x_{\mathrm{q}}
$$

i.e., that the second member of static Eq. (2) and the second member of dynamic power Eq. (3) are not cancelled and we need to count with them in the stability calculation.

\section{GRAPHICAL REPRESENTATION OF THE SYNCHRONOUS ALTERNATOR 588 MVA STABILITY (EME III)}

Theory and practical laboratory and operational experience used to calculate these courses of variables are taken from own research and laboratory experience in the Research Institute of Power Electrotechnics (VUSE Běchovice, Prague) and from the references [3], [4].

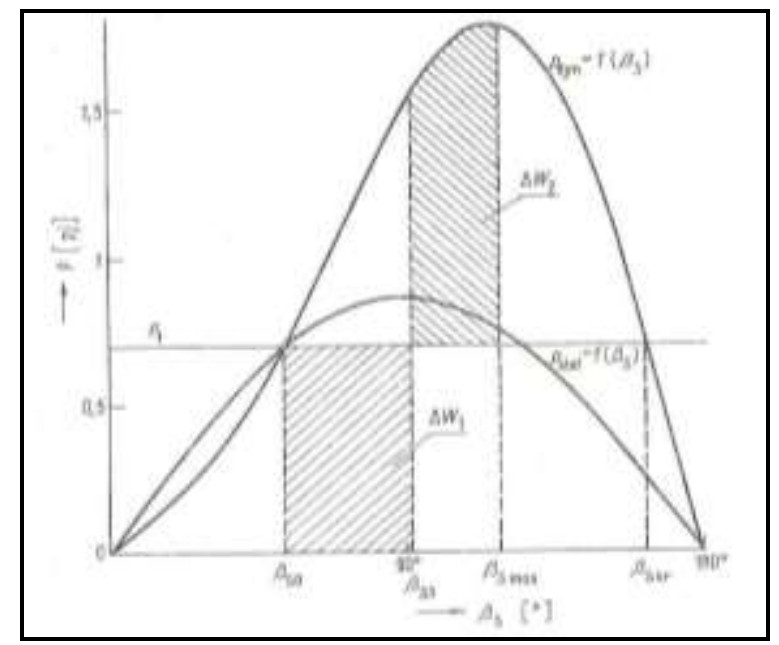

Fig. 1. Curves of static and dynamic performance characteristics of the alternator 588 MVA, with cylindrical rotor.

To block transformer the short circuit was for $0.2 \mathrm{sec}$, during which the rotor spends excess energy W1.

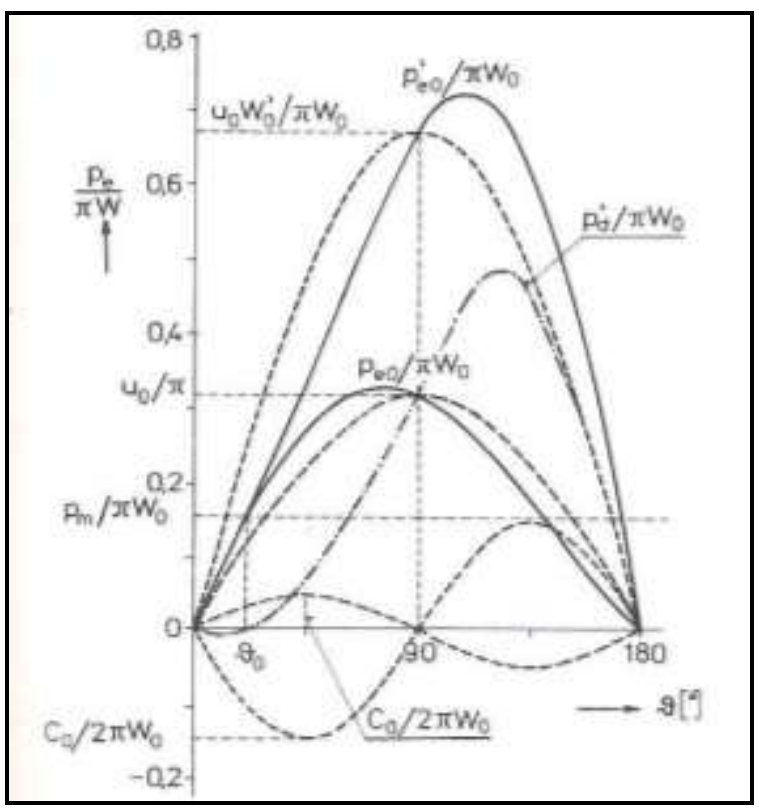

Fig. 2. Static $\left(\mathrm{p}_{\mathrm{e} 0} / \pi \mathrm{W}_{0}\right)$ and dynamic $\left(\mathrm{p}^{\prime}{ }_{\mathrm{e} 0} / \pi \mathrm{W}_{0}\right)$ performance characteristics of synchronous machines, with salient poles. 
In Fig. 2 there are shown theoretical static and dynamic performance characteristics, calculated according to Eqs. (2), (3), where the "dot-and-dash" lines indicated sequences of the first and second harmonic components, and the "dash" course of the synchronous dynamic performance.

The figures are clear for the following facts:

The actual course of the "dynamic stability" has a slightly higher maximum shifted from $90^{\circ}$ to the right (Eq. (3)). This will slightly reduce the area of accelerating and the braking area is considerably larger.

In practical terms, it is favorable, because the duration of the permissible short-circuit (CCT) is slightly larger.

From Fig.1 it were for the "dynamic stability" graphically subtracted areas: accelerating and braking. Change in the "accelerating" area from the graphic course between one and two-member formula is negligible. The "braking" area from graphics, however, for the two-member equation is increased by $34 \%$.

It can therefore be given an illustrative example: If for one-member equation $\mathrm{CCT}_{1}=160 \mathrm{~ms}$, then for twomember formula $\mathrm{CCT}_{2}=215 \mathrm{~ms}$ (34\% larger). In the first case it can be set to protect time $150<160 \mathrm{~ms}$. In the latter case, however, up to $\mathbf{2 1 0}<215 \mathrm{~ms}$, which already allows the implementation of the Special Protection Schemes (SPS) and local automatics, based on using of the synchrophasor measurement unit PMU, synchronized by GPS and/or GALILEO system.

From the previous figures it is obvious that when using the single-member equations for static and dynamic stabilities it is always considered greater stability, respectively higher operating margin of stability, than in the case of two-member equations. It should be noted that the standard single-member equations are used for the stability calculation of the Czech distribution companies (CEZ Distribution, E.ON, PRE) as well as the Czech transmission system operator TSO CEPS.

In response to this fact I note that if it is currently good to choose always systematically larger stability margin than it is technically necessary (when using an equationmember), but I do not think it is right in the near future.

\section{THE DYNAMIC STABILITY OF THE SYNCHRONOUS ALTERNATOR 1111 MVA (JETE VVER 1000)}

From the calculations [12] the following conclusions were made:

1. In the operating states of the electrification system, which require a minor over-excitation of the alternator and in unfavorable configuration in the HV line connection, the alternator operation may be on the limit of the static stability. This state may be further affected by a failure of another line. Operating states in these cases require the excitation regulators to be permanently operated with the Power Systems Stabilizer (PSS), which favorably affects the static stability limit.

2. The static excitation system must be used because it has good properties.
3. In order to increase the operating range of the permitted excitation limits, it is advisable and useful to use the Turbine Valve Speed Control (TVSC), especially for those network failures that threaten the dynamic stability of the alternators (e.g., a nearthree-phase short-circuit which means the failure of the affected line).

4. The calculated simulated efficiency of the TVSC depends on the turbine model used (simple IEEE model or realistic model with nonlinearities and actual properties) and the time lag between the occurrence of the fault and the initiation of the TVSC signals (Critical Clearing Time - CCT). Based on these facts, it is strongly recommended to shorten the initiation signal delay to a minimum, and to perform a power response on the initiating signals with a minimum delay (less than $0.2 \mathrm{sec}$ ).

\section{SiMUlators OF LARGE POWER Plants}

Using SSCG allows researchers to search for solutions for problems inherent to smart systems, such as a balance between production and consumption, peak management, renewable energy integration and storage, and energy saving.

1. Simulators of nuclear power plants interconnected in transmission systems

Scope of one NPP unit modeling is in accordance with the applicable standards for nuclear power plants, but Smart Simulator modeling is insufficient. At such a simulator cannot simulate parallel operation of more generators and therefore it is not a realistic island regime with more energy sources - power units.

2. Simulators of power and heating plants interconnected in transmission or distribution systems

For the power plant Opatovice (EOP) transient simulation calculations were performed and the ability of island operations evaluated. It cannot only prevent damage to the electrical system, but also to ensure a successful operational implementation, and required certification of the island operation [5]. Principles of smart grids of the electrical and thermal energy generation and heat consumption control are within the district heating networks [8].

\section{SMART SIMULATORS GRID}

Smart Simulators of Complex Grids (SSCG) must include not only the narrowly defined technological part of the power system, but must extend to neighboring areas. For example, the simulation models must not include only the power plant but also led out electrical power to the distribution or transmission system [5]. Using SSCG allows researchers to search for solutions for problems inherent to smart systems, such as a balance between production and consumption, peak management, renewable energy integration and storage, and energy saving [7]. Very important is also simulation model of a smart grid with an integrated large heat source [13].

1) Smart training simulator of power plant electricity substations in island mode operation

In terms of a simulation of the island regime and more parallel generators simulators of electrical substations are advanced, because such modelling is in this case quite normal [3]. 


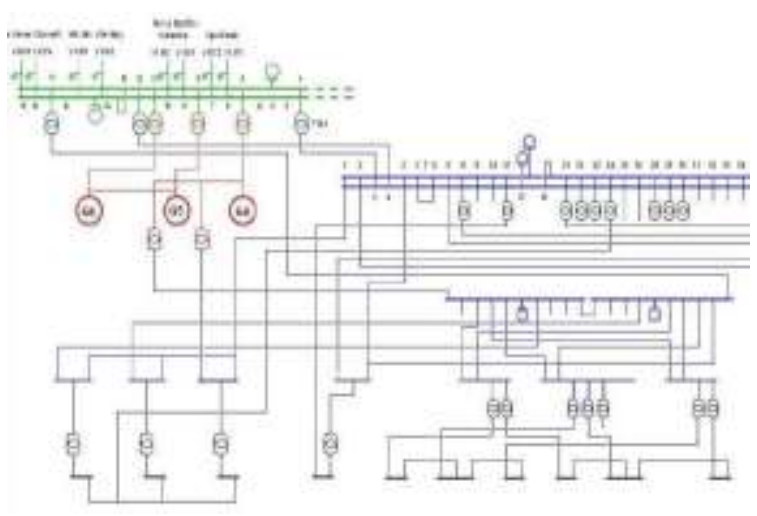

Fig. 3. Half of the single-line diagram of substations of EOP.

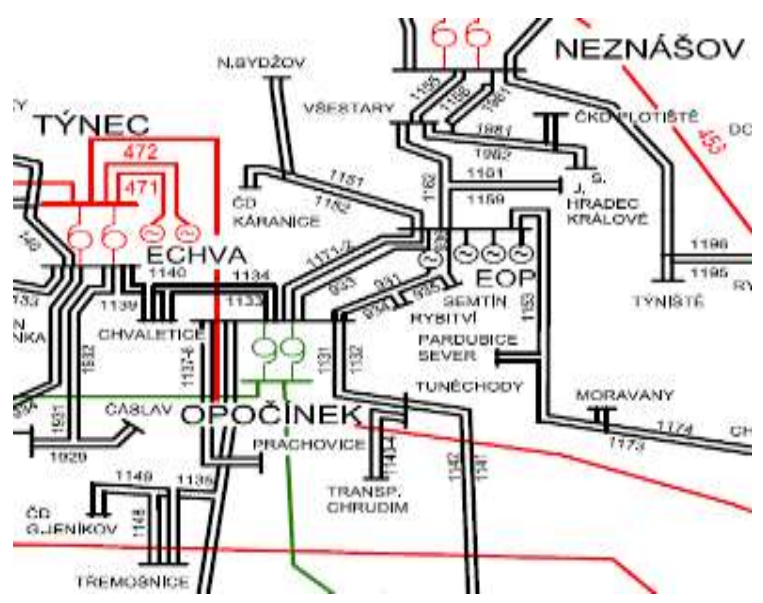

Fig. 4. Single-line diagram of the distribution system region (black lines $-110 \mathrm{kV}$ ) for power plant EOP.

The following Figs. 5 - 9 have the purpose to show the monitors that the operator can see during training.

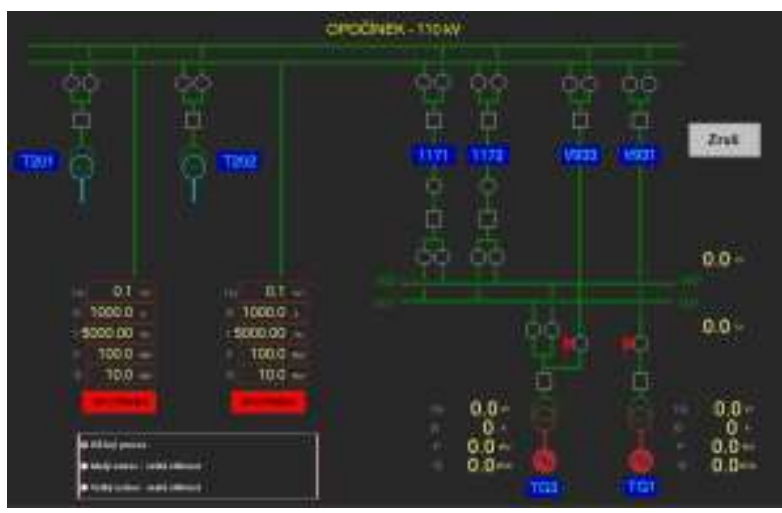

Fig. 5. SCADA mimics with a choice of network size (given the $\mathrm{K}$-factor size), Legend $($ Czech = English $)$ :

Běžný provoz = Infinite power grid

$($ K-factor $=16000-20000 \mathrm{MW} / \mathrm{Hz} \ldots$ ENTSO-E)

Malý ostrov = $\quad$ Small power grid

(K-factor $=30-100 \mathrm{MW} / \mathrm{Hz} \ldots$ EOP and own consumption)

Velký ostrov $=$ Intermediate power grid

(K-factor $=600-1000 \mathrm{MW} / \mathrm{Hz} \ldots$. Czech Rep. and 1.circuit)

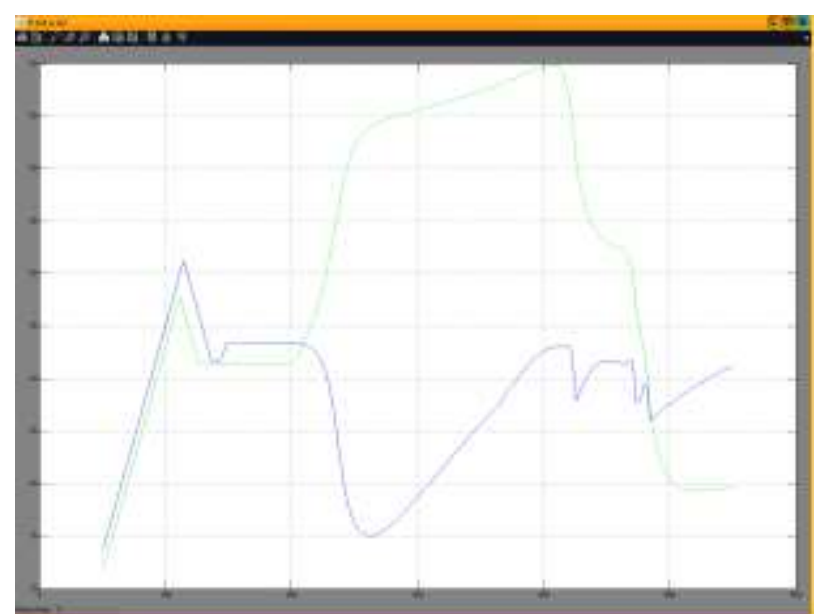

Fig. 6. Time courses of the active power generators G2 and G4.

Legend:

within $115 \mathrm{~s}$... move to power (G2 - green line, G4 - blue)

$115 \mathrm{~s}$...both generators connected to infinite power grid

$200 \mathrm{~s}$... switched on intermediate power grid (Opoč)

$360 \mathrm{~s} . .$. switched on small power grid (Opoč)

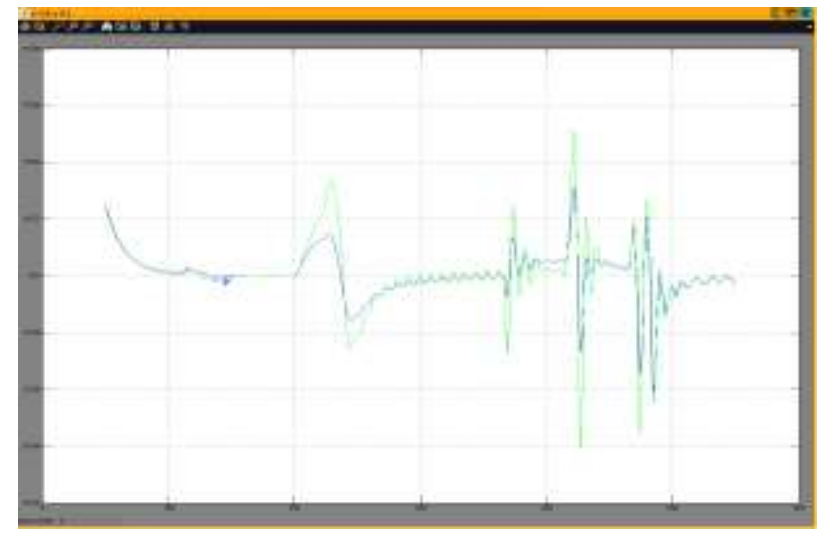

Fig. 7. Time courses of the generators G2 and G4 voltages.

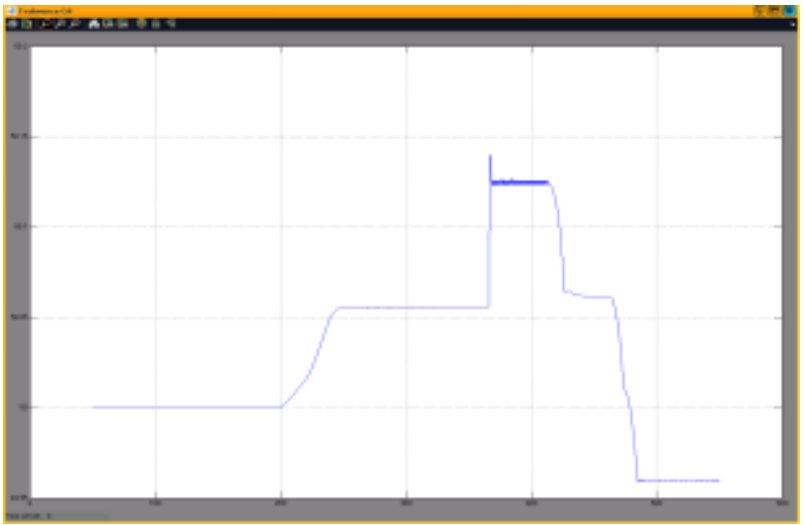

Fig. 8. Time course of the generator G4 frequency. 


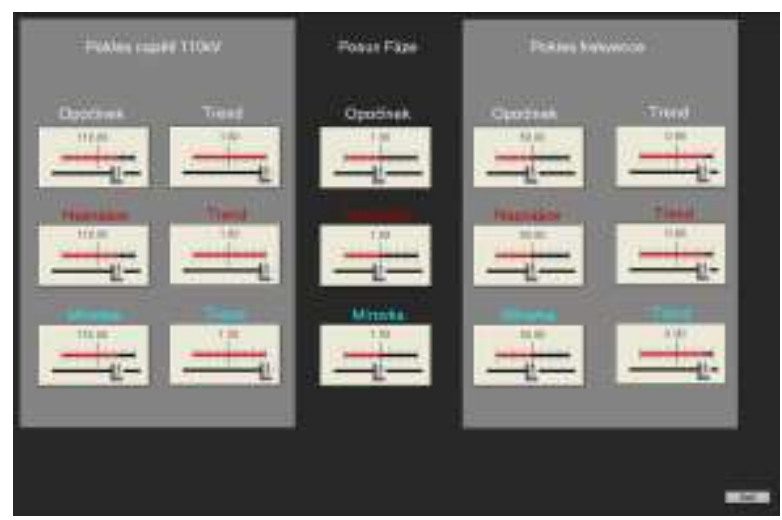

Fig. 9. Instructor operation screen for changes on the substation Opočínek $=$ OPOC, Neznášov $=$ NEZ, Mírovka $=$ MIR.

(Translation: Pokles napětí $=$ voltage drop, Posun fáze $=$ phase shift, Pokles frekvence $=$ decrease in frequency)

\section{2) Training Simulator NPP Flamanville FA3 EPR}

The following figure shows the screen operator training simulators of a nuclear power plant. This is the OTS Flamanville FA3 with the EPR nuclear reactor built in France, where the instructor can choose leading out electrical power to small power grid (400 MW), or intermediate power grid (45000 MW), or infinite power grid - see Fig. 10. There are high-end dynamic grid electrical models of different grid configurations (infinite, 45000 MW, $400 \mathrm{MW}$ ) available for external network modelling. Significant impact on voltage and frequency regulations depends on the selected configuration (stringent transients). Enhanced training drills for plant and grid operators during which the nuclear station behaviour and operator action (primary and secondary regulations, T\&G settings) can be checked / verified [2].

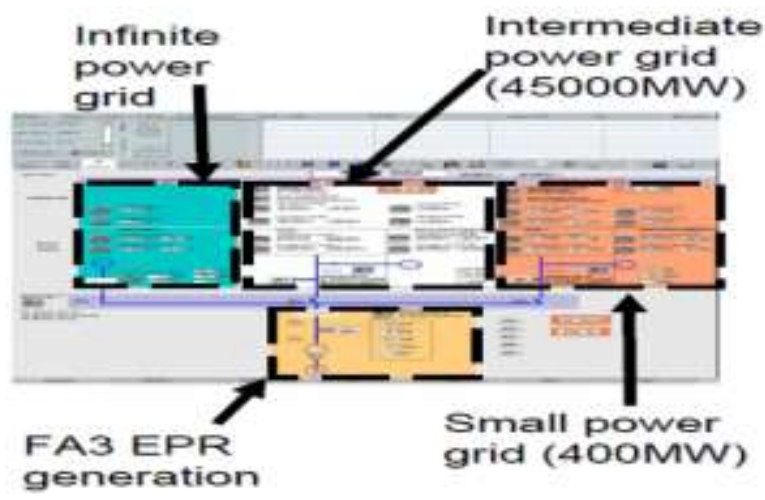

Fig. 10. High-end dynamic grid electrical models.

The simulator FA3 EPR is modelling all voltage losses scenarios (external grid, main generator, emergency external grid, emergency diesel generators, ultime emergency diesels and batteries), until complete blackout overdays (all actuators power dependencies, all I\&C voltage dependencies) and complete plant restart Blackstart - see the color markings in Fig. 11.

The Fukushima nuclear disaster will not do much to change the basic political economy of atomic energy. Defensive reaction of the nuclear industry repositioned politicians and policymaker pose. Scarce and expensive energy will likely support building of new nuclear plants in the coming decades.
3) Training Simulator NPP Temelin JETE VVER 1000

Scope of one NPP unit modelling is in accordance with the applicable standards for nuclear power, but smart simulator modelling is insufficient.

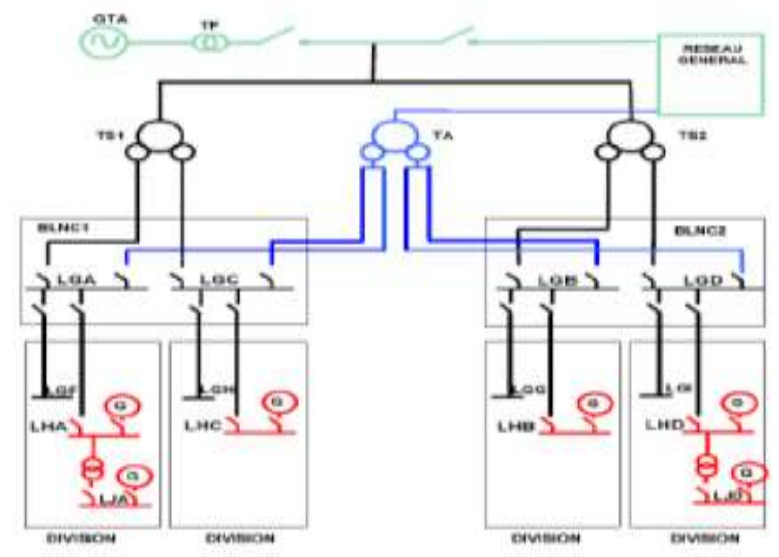

Fig. 11. High-fidelity electrical distribution scenarios - NPP FA3 EPR.

Basic thermohydraulic models for 5- and 6-equation solutions are used [7]. These models are based on the "first principle".

Five of the conservation equations are following:

1. mass of the liquid phase,

2. mass steam phase,

3. energy for the liquid phase,

4. energy for vapour phase,

5. momentum equations of liquid and steam mixture (their separation is solved by drift-flux model / drift-flux correlation),

6. mass for non-condensable gases.

The nuclear project engineer or operator of a nuclear power plant cannot imagine that the steam generator model will not be modelled without condensation of steam in the pipes "risers", for which it is necessary to use a 5or 6-equation thermohydraulic model.

The 5- or 6-equation thermohydraulic model is complicated and takes a long calculation [10]. The numerical integration step is in the case of NPP Temelin $\mathrm{T}_{\mathrm{i}}=80[\mathrm{~ms}]$.

Setting of the Power System Stabilizer (PSS), whose purpose is to dampen low frequency oscillation of the synchronous generator rotor [14], corresponds to the division of electromechanical swinging into three categories:

1. Inter-Area oscillations: Typical range 0.2 to $0.5 \mathrm{~Hz}$.

2. Local oscillations: Typical range 0.7 to $2.0 \mathrm{~Hz}$.

3. Oscillations between the machines: 1.5 to $3.0 \mathrm{~Hz}$.

This (training or engineering) simulator with the numerical integration step $\mathrm{T}_{\mathrm{i}}=80$ [ms] cannot realistically simulate oscillations ad 1,2 , and it can only partially simulate oscillations ad 1. [11]. Numerical instability may not be obvious, and it may seem that the synchronous generators with excitation system are unstable. For the model of a coal power block such a request is irrelevant [8].

For such blocks it is fully sufficient only the 3-equation model (homogeneous model). Five of the conservation equations are following: 
1. Mass liquid and steam.

2. Energy for the liquid and steam phase.

3. Momentum equations of liquid and steam mixture. In this case, we can achieve the numerical integration step $\mathrm{T}_{\mathrm{i}}=10$ milliseconds.

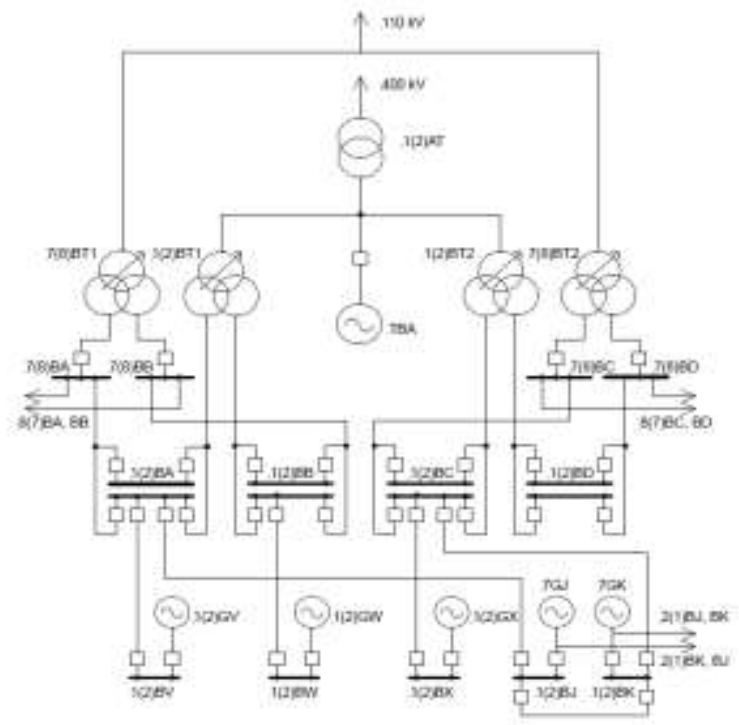

Fig. 12. Schematic diagrams of power supply B1 NPP Temelin (JETE) - one of two parallel blocks (B1, B2).

In the coming years we could expect that the standards for nuclear unit simulators will require a more realistic simulation of not only one unit, but all NPP units and their connection to the electricity grid. These requirements are derived from the results of the stress tests that were carried out after the accident at the NPP Fukushima [7].

One possibility is use of the two block simulator of the nuclear power plants, but the primary part (nuclear reactor) would be modelled as an analytical simplified model. As a full-scope model it would be the "turbinegenerator" and electrical block substation with output of electrical power into the electrical grid see Table II.

TABLE II

ALTERNATIVES OF THE SIMPLIFIED ANALYTICAL SIMULATORS FOR ONE AND TWO NPP BLOCKS

\begin{tabular}{|c|c|c|}
\hline & UNIT 1 & UNITS 1,2 \\
\hline $\begin{array}{l}\text { Existing } \\
\text { current } \\
\text { Simulator NPP } \\
\text { block 1 }\end{array}$ & $\begin{array}{l}\text { Detailed full scope: } \\
\text { reactor block } 1 \text { (B1) - } \\
\text { Turbo-Generator } \\
\text { blocks 1 (TGB1) - } \\
\text { auxiliary equipments }\end{array}$ & $\mathrm{X}$ \\
\hline $\begin{array}{l}\text { Analytical } \\
\text { Simulator NPP } \\
\text { blocks } 1,2\end{array}$ & $\begin{array}{l}\text { Detailed full scope: } \\
\text { reactor B1 - TGB1 - } \\
\text { auxiliary equipments } \\
\text { B1; } \\
\text { Generic scope: } \\
\text { Simple power reactor } \\
\text { B2 - detailed TGB2 } \\
\text { Detailed: substations } \\
\text { - leading electric } \\
\text { energy } 400 \mathrm{kV} \\
\text { Alternative: extension } \\
\text { of the existing display } \\
\text { type simulator }\end{array}$ & $\begin{array}{l}\text { Analytical /Generic } \\
\text { scope: } \\
\text { Simple reactor B1 - } \\
\text { detailed TGB1 - } \\
\text { auxiliary equipments } \\
\text { B1; } \\
\text { Generic scope: } \\
\text { Simple reactor B2 - } \\
\text { detailed TGB2 } \\
\text { Detailed: substations - } \\
\text { leading electric energy } \\
400 \mathrm{kV} \\
\text { Alternative: extension of } \\
\text { the existing display type } \\
\text { simulator }\end{array}$ \\
\hline
\end{tabular}

Such a solution, however, prevents the current legislative and operational regulations applicable to nuclear power plants. Changing regulations can be expected in the future, when the results of the study stress tests after the nuclear accident in Fukushima will be fully implemented into regulations. However, it may take even ten years.

\section{CONCLUSION: CONCEPT SMART GRID / SIMULATORS}

Liberalisation of the electricity supply industry causes new operation requirements and training needs for staff members in the power system control. Market principles lead to a more customer and quality oriented business with increasing interest in reliable system operation. The simulator based training is proved during the past years to be beneficial for improving the operator performance. Embedded in tailor made courses to company's (ies') needs this kind of training supports the knowledge, the practical skills and experience in the control centres to ensure the quality of power system operation.

References are not a simulation overview tools for smart grids. For the simulation authors used exclusively MATLAB - SIMULINK - SimscapePowerSystems (SPS), based on own long experience. The simulation of grids (containing also nuclear and renewable power sources) is very important, in particular for the operator training in industrial practice. Even if there had not been a scientifically significant new aspect or approach.

It is necessary to simulate the rapid changes in the power of individual NPP units, and for these regimes to train operators of nuclear units. Current requirements on the simulator functions of nuclear blocks do not contain such regimes (i.e. simulators Czech NPP Temelin and NPP Dukovany such regimes cannot simulate).

Concept Smart Grid is a major tool intended to study and test electrical systems of the future. Wholly dedicated to "smart" systems, this experimental platform makes it possible to perform complex tests that would be impossible to perform on a real grid.

\section{REFERENCES}

[1] Arrillaga J. and C.P. Arnold (1994). Computer Analysis of Power Systems. John Wiley \& Sons, Chichester, 1994.

[2] Gain, P. (2011). Powering Simulation Certainty - View the future today. CORYS Users Club 2011, Grenoble, France.

[3] Hamata, V, and J. Cemus (1984). The general solution to the dynamics of synchronous machines (in Czech). Publishing House ACADEMIA, Prague.

[4] Hora, O. et al. (1985). Regulatory and excitation systems for synchronous machines (in Czech). Library Automation, no.78, Publishing House SNTL, Prague.

[5] Neuman, P. (2009). "Models of synchronous generator and transformers for dispatch training simulators and real time digital simulators". In Proceedings of IFAC Symp. on Control of Power Systems and Power Plants, Tampere, Finland. https://doi.org/10.3182/20090705-4-sf-2005.00070

[6] Neuman, P. (2011). "Smart Grid methods of Transmission System Operators for improved Power System Control". In Proceedings of IFAC World Congress, Milan, Italy.

[7] Neuman, P. (2012). "Power Plant and Turbogenerator models for Engineering and Training Simulators". In Proceedings of IFAC Symp. on Control of Power Systems and Power Plants, Toulouse, France.

https://doi.org/10.3182/20120902-4-fr-2032.00056

[8] Neuman, P., et. al. (2014). "Principles of Smart Grids on the generation electrical and thermal energy and control of heat 
consumption within the District Heating Networks". In Proceedings of 19th IFAC World Congress, Cape Town, South Africa. https://doi.org/10.3182/20140824-6-za-1003.00553

[9] Neuman, P. and Jirkovsky, J. (2015). "Power Systems: Synchronisation of Synchronous Generator in Engineering and Training Simulators". Transactions on Electrical Engineering, Vol. 4 (2015), No. 2. pp. 42-50.

[10]Peca, R. (2015). Nuclear Power Plants Training Simulators (in Czech). The cycle E2015, no. 8. Prague, Czech Republic.

[11]Schrumpf, L. (2007). Full Scope Operator Training Simulators of Power Plants (in Czech). 12 $2^{\text {th }}$ International Energy Conference, Poděbrady, Czech Republic.

[12] Trojanek, Z. Krecek, J. (1986). Dynamic Stability of Synchronous Alternator $1000 \mathrm{MW}$ of Nuclear Power Plant Temelin JETE (in Czech). Technical Report, Czech Technical University in Prague,
Faculty of Electrical Engineering, Department of Electroenergetics, Prague, Czech Republic.

[13] Vasek, L., Dolinay, V., Vasek, V. (2014). "Simulation Model of a Smart Grid with an Integrated Large Heat Source". In Proceedings of 19th IFAC World Congress, Cape Town, South Africa. https://doi.org/10.3182/20140824-6-za-1003.01145

[14]Weber, H., (1997). "New Frequency and Power Oscillations in the Enlarged Westeuropean Interconnected Network Reasons and Counter Measures". Preprints of the IFAC/CIGRE Symposium on Control of Power Systems and Power Plants, Beijing, China. https://doi.org/10.1016/s1474-6670(17)46390-7

[15] Weber, H., AlAli, S., Hasse, T., Nassar, I., (2014). "Impact of Increasing Wind Power Generation on the North-South Inter-Area Oscillation Mode in the European ENTSO-E System". In Proceedings of 19th IFAC World Congress, Cape Town, South Africa. 